\title{
Porosity of different thickness of acrylic polymerized by different methods.
}

Luay N Abood

BDS, MSc (Assis Lect)

\author{
Department of Prosthetic Dentistry \\ College of Dentistry, University of Mosul
}

\begin{abstract}
Aims: To evaluate the porosity that occur in the acrylic resin denture base polymerized by the microwave cycle and conventional water bath with two different thickness, relation between the thickness of specimen and its percentage of porosity. Material and methods: Forty rectangular resin specimens with the following dimensions $(65 \times 40 \times 6 \mathrm{~mm}),(65 \times 40 \times 3 \mathrm{~mm})$ were subdivided according to polymerization method into microwave cycle and conventional heat polymerization method to obtain 10 specimens with different polymerization method and thickness, for each one of 4 groups. Porosity was calculated by measure the specimen volume before and after its immersion in water, data were analyzed by student $t-$ test analysis at $(\mathrm{p}<0.05)$. Results: Showed that specimens of $(6 \mathrm{~mm})$ that cured by microwave polymerization method showed significantly higher percentage of porosity when compared to the same thickness of conventional water bath polymerized acrylic resin at $(\mathrm{p}<0.05)$, while no significant difference between the percentage porosity of the conventional and microwave heat cured acrylic resin of $(3 \mathrm{~mm})$ thickness specimens. Also there is no significant difference between the thickness of specimen and the conventional water bath method of heat cured acrylic resin. While for microwave curing method of heat cured acrylic resin there is significant difference for increase of percentage of porosity with increase of thickness of specimens. Conclusions: The conventional acrylic resin of $(\geq 3 \mathrm{~mm})$ specimens thickness can be polymerized with microwave curing method safely with less porosity, while for $(\geq 6 \mathrm{~mm}$ ) specimens thickness is preferred to be polymerized by conventional water bath curing method.
\end{abstract}

Key words: Acrylic resin, porosity, polymerization method.

Abood LN. Porosity of different thickness of acrylic polymerized by different methods. Al-Rafidain Dent J. 2007; 7(2): 173-179.

Received: $30 / 5 / 2006 \quad$ Sent to Referees:31/5/2006

Accepted for Publication: $31 / 7 / 2006$

\section{INTRODUCTION}

Acrylic resin have been used for denture fabrication for over 60 years, firstly were utilized as denture base materials in 1937. ${ }^{(1)}$ poly (methyl methacrylate) is the primary base resin used today. ${ }^{(2)}$ There has been many searches to modify the processing procedures of the resin to improve not only physical and mechanical properties but also the working properties that facilitate laboratory techniques of denture construction. ${ }^{(3)}$

The polymerization of denture base resin by microwave energy has been studied for more than three decades. ${ }^{(4)}$ The advantages of polymerizing denture base resin by microwave energy are a greatly reduced polymerization time, and cleaner method of processing. ${ }^{(5,6)}$ Although most physical properties of denture base resin polymerrized by microwave energy proved are sim- ilar to resins polymerized by conventional heat method. The conventional acrylic resins used for the production of denture base can also be used in microwave method. ${ }^{(5,7,8)}$

There is no significant difference between the microwave polymerization cycles with different wattage and time in comparison with control group of conventional water bath., also no porosity when the resin made specifically for microwave polymerization, especially when resin thickenss exceeded $3 \mathrm{~mm}^{(7)}$, when the denture base resin was polymerized in the microwave with along or short cycle, the high wattage with short cycle produced more porosity in the thick specimens than that of the lower wattage with longer cycle. ${ }^{(8)}$

The usage of long cycle with low voltage (30 minutes at low setting 80 watt and followed by 1.5 minutes at high wattage 
1500 watts for removal of excess monomer) produce less porosity than other techniques in comparison to the conventional water bath technique. ${ }^{(9)}$

Porosity has been attributed to a variety of factors that include the followings: air entrapped during mixing, monomer contraction during polymerization, monomer vaporization associated with the exothermic reaction and the presence of residual monomer, insufficient mixing of monomer and polymer, processing temperature higher than $74{ }^{\circ} \mathrm{C}$, packing the mold and inadequate compression on the flask may cause porosity in denture base resin. ${ }^{(10,11)}$ There is significant decrease of residual monomer of polymer that is unpolymerized obtained when a resin cured at $70^{\circ} \mathrm{C}$ followed by a period at $100^{\circ} \mathrm{C}$ than curing at $70^{\circ} \mathrm{C}$ only. ${ }^{(12)}$

There are different methods to measure the porosity, either when surface area of $1 \mathrm{~cm}^{2}$ was delimited in the center of each specimen and observed under 40x magnification, the number of pores per area was calculated for each specimen and an average value was delivered for each group ${ }^{(13)}$, or by cuting the specimens 3 -cross sectional areas and photographed under a microscope at its 100x magnification, the area of each pore was measured with a planimeter and total pores area per surface area of all samples calculated in percentage form. ${ }^{(8)}$

others measured the porosity by weighed the specimen in air and in water and used equations to calculate percent mean porosity for the specimen. ${ }^{(7)}$

The aim of this study is to evaluate the porosity that occur in the acrylic resin denture base polymerized by the microwave cycle and conventional water bath with two different thickness and relation between the thickness of spacemen and its percentage of porosity.

\section{MATERIALS AND METHODS}

Forty rectangular acrylic specimens of Major Base 2 (Major Prodotti Dentari S.P.A, Italy), 20 specimens of $(65 \times 40 \times 3 \mathrm{~mm})$ dimensions and the remaining 20 specimens of $(65 \times 40 \times 6 \mathrm{~mm})$ dimensions. ${ }^{(14)}$ They samples were divided in to 4 groups consist of 10 specimens each 20 specimens of different dimensions cured with microwave and other remaining 20 specimens were cured by water bath.

Wax master patterns (Poly wax, Bilkim Chemical Co., Izmir; TURKEY) were individually invested in a dental stone (Elite Model dental stone; Unicgien, Zhermack, Italy) with in flasks. For the microwave curing fiber glass flasks were used (Fiber Re-inforced Plastic Flask), and for water bath curing Ash metal flasks (Ash, England) were used. After the investing material had set, the flask was placed in the microwave oven, to soften the wax, it was microwaved for 1 minute at high setting (500 watts). Then, the flask was opened and flush both parts thoroughly with boiling water and detergent.

The same method described in waterbath technique was used, also same thing for application of separating medium, mixing, and packing of acrylic resin. acrylic resin was mixed according to the manufacturer instructions and each specimen mixing ratio of $10 \mathrm{ml}$ of monomer and $30 \mathrm{ml}$ of polymer and left to rest in the covered glass jar for the dough time ${ }^{(7)}$, then the mixture packed in to the stone mold in the flask. A gauge press (Bego, Hydrofix, Germany) used to pack the acrylic resin at 1500 psi till the excess of material appeared from the peripheries of the flask ends and still under press for about 10 minutes. Twenty specimens of two different dimension groups cured in the ash metal flasks in thermostatically controlled curing unit (Kavo GmbH, West Germany), at $70{ }^{\circ} \mathrm{C}$ for 30 minutes then proceed at $100{ }^{\circ} \mathrm{C}$ for 30 minutes (according to the manufacturer instructions), in a thermostatically controled water bath then the flasks were left aside for slow bench cooling before opening.

The curing for the remaining $20 \mathrm{spec}-$ imens of two different dimensions done by microwave cycle. The microwave oven that used in this study was a lateral wave microwave oven. It was an ordinary household microwave oven, with 500 watts, maximum output representing the high level of control setting, and its minimum output was 80 watts, representing low level output. The frequency of this oven was $2450 \mathrm{MHz}$ and was has turntable instead of stirrer, in order to give even distribution of microwaves through the heated material 
(Figure1). After packing of acrylic resin in the fiber glass flasks done Teflon nuts and washers were placed in their correct position and the nuts were tightened securely. For curing of acrylic resin, the FRP flask was placed in the microwave oven for 30 minutes at the low setting ( 80 watts), 15 minutes per side, followed by 1.5 minutes at the high setting (500 watts). ${ }^{(8)}$ then the flask was left aside for slow bench cooling before opening. The excess resin was trimed from all specimens using carborandum disk (DRAFA Comp., West Germany) and each specimen was finished by using 400 grit wet/dry sand paper (Norton: Brazil) in mandrill bur (DRAFA Comp., West Germany) by using laboratory engine (W \& $\mathrm{H}$ Dental Werk, Bürmoos, GmbH, Austria).

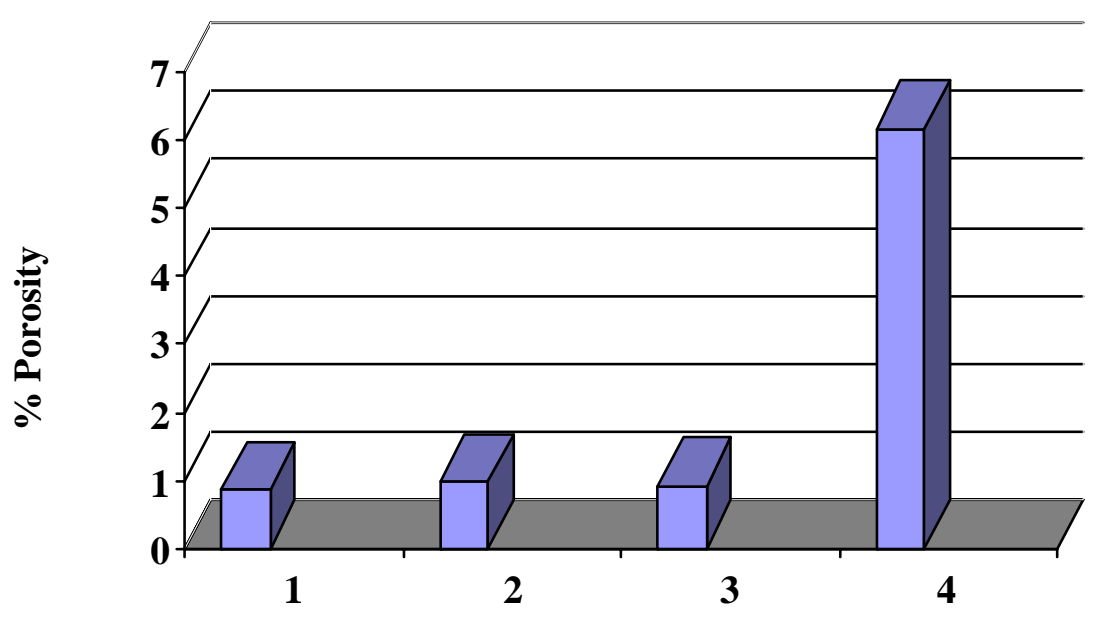

Figure (1) Distribution of porosity values.

1: Conventional heat cured acrylic resin $(3 \mathrm{~mm})$ thickness; 2: Microwave heat cured acrylic resin $(3 \mathrm{~mm})$ thickness; 3 : Conventional heat cured acrylic resin $(6 \mathrm{~mm})$ thickness; 4: Microwave heat cured acrylic resin $(6 \mathrm{~mm})$ thickness.

Before testing, the specimens were dried in a desiccator (Corning Brazil; Indu' stria Come'rcio Ltd, Sao Paulo, SP, Brazil) containing silica gel for 7 days. ${ }^{(10)}$ Processed specimens were weighed in a $0.00001 \mathrm{~g}$ with analytical balance (Sartorius; Sartorius AG, Gottingen, Germany) until a constant weight was achieved. Each specimen was weighed in air (with out using of a beaker of water) and in water (by using beaker of clear glass of 1 liter filled with water). All readings for each sample (weight in air and weight in water) were recorded.

To calculate percentage mean porosity, by using absolute density of acrylic resin the percent mean porosity obtained with the aid of the following equations ${ }^{(7)}$.

$\mathrm{Wa}=\mathrm{g}(\mathrm{dr}-\mathrm{da})(\mathrm{Vsp}-\mathrm{Vip})$.
$\mathrm{Ww}=\mathrm{g}(\mathrm{dr}-\mathrm{dw})(\mathrm{Vsp}-\mathrm{Vip})+(\mathrm{da}-\mathrm{dw}) \mathrm{Vip} \ldots[$ [2]

$\%$ of porosity $=\mathrm{Vip} / \mathrm{Vsp} \times 100 \ldots \ldots \ldots \ldots . .$. [3]

where $\mathrm{Wa}=$ Specimen weight in air;

$\mathrm{Ww}=$ Specimen weight in water; $\mathrm{g}=$ gravitational constant; $d r=$ density of acrylic resin; $d a=$ density of the air; $d w=$ density of the water; $\mathrm{Vsp}=$ specimen volume, and Vip= internal porosity volume. In eqation [1], specimen volume minus volume of internal porosity was determined using the following known values: $\mathrm{dr}=1.198 \pm 0.01$ $\mathrm{g} / \mathrm{ml}, \mathrm{da}=1.23 \mathrm{~kg} / \mathrm{m}^{3}, \mathrm{dw}=1000 \mathrm{~kg} / \mathrm{m}^{3}$ and $\mathrm{g}=9.8066 \mathrm{~m} / \mathrm{sec}^{2}$ after solving the first equation for specimen volume minus volume of internal porosity, this value was used in the second equation, with the $\mathrm{Ww}$ measured, to calculate the volume of internal porosity. With known values for specimen volume minus volume of internal po- 
rosity, by calculating the specimen volume, divided in to the volume of internal porosity and multiplied by 100 to obtain total percent porosity value for each specimen (equation [1]).

Data collection were statistically analyzed using student $t$-test analysis to determine the effect of polymerization method and thickness of specimen on the porosity of acrylic resin at $(\mathrm{p}<0.05)$.

\section{RESULTS}

The mean values, standard deviations of the specimens, weight in water, weight in air, internal porosity volume, percentage of porosity for each group and specimen volume are shown in Table (1).

Table (1): Descriptive statistics for all groups

\begin{tabular}{ccccccc}
\hline Group & $\mathbf{N}$ & $\begin{array}{c}\text { Ww (g) } \\
\text { Mean } \pm \text { SD }\end{array}$ & $\begin{array}{c}\text { Wa (g) } \\
\text { Mean } \pm \text { SD }\end{array}$ & $\begin{array}{c}\text { Vip (ml) } \\
\text { Mean } \pm \text { SD }\end{array}$ & $\begin{array}{c}\text { Vsp (ml) } \\
\text { Mean } \pm \text { SD }\end{array}$ & $\begin{array}{c}\% \\
\text { Porosity }\end{array}$ \\
\hline $\begin{array}{c}\text { C.h.a. } \\
\text { 3mm }\end{array}$ & 10 & $1.753 \pm 0.041$ & $10.187 \pm 0.113$ & $0.0687 \pm 0.035$ & $7.8 \pm 0.000$ & 0.87 \\
$\begin{array}{c}\text { M.h.a. } \\
\text { 3mm }\end{array}$ & 10 & $1.612 \pm 0.056$ & $10.207 \pm 0.109$ & $0.0768 \pm 0.121$ & $7.8 \pm 0.000$ & 0.98 \\
$\begin{array}{c}\text { C.h.a. } \\
\text { 6mm }\end{array}$ & 10 & $3.131 \pm 0.139$ & $18.055 \pm 0.203$ & $0.144 \pm 0.038$ & $15.6 \pm 0.000$ & 0.92 \\
$\begin{array}{c}\text { M.h.a. } \\
\text { 6mm }\end{array}$ & 10 & $2.030 \pm 0.1022$ & $18.073 \pm 0.265$ & $1.071 \pm 0.071$ & $15.6 \pm 0.000$ & 6.16 \\
\hline
\end{tabular}

N: Number of samples; C.h.a: Conventional heat cured acrylic resin; M.h.a: Microwave heat cured acrylic resin; Ww: Specimen weight in water; Wa: Specimen weight in air; Vip: Internal porosity volume; Vsp: Specimen volume; SD: Standard deviation; *: SD is 0.000 because the size of sample fixed.

The porosity percentage values for all groups are represented by Figure (1). Student $t$-test analysis showed significant difference in mean porosity percentage of the two groups of different curing methods of (6mm) thickness specimen, (Table 2) which showed that microwave heat cured acrylic resin of thick specimen $(6 \mathrm{~mm})$ had nearly $6 \%$ porosity when compared to $0.92 \%$ of conventional heat cured acrylic resin specimen of the same thickness. While no significant difference between the two groups of $(3 \mathrm{~mm})$ thickness specimen of conventional and microwave heat cure acrylic resin (Table 3). Also student t-test analysis for the percentage porosity of the two different thickness (effect of thickness on polymerization method) specimens for microwave heat cured acrylic resin showed significant difference in percentage of porosity (Table 4), while no significant difference between the two different thickness specimens of conventional heat cure acrylic resin (Table 5).

\section{DISCUSSION}

The formation of porosity in poly methyl methacrylate (PMMA) is a complex phenomenon with multifactorial origin. Porosity may be depends on polymerization methods, material, thickness of specimen. The methods that used in the present study did not showed significant difference between the thin specimens whatever the type of polymerization methods.

However the thick specimens $(6 \mathrm{~mm})$ that cured by microwave polymerization method showed significant difference in porosity percentage when compared to the same thickness of conventional water bath polymerized acrylic resin specimens and this finding in agreement with others. ${ }^{(15)}$

The thicker the specimen the more pores are exhibited (more than $3 \mathrm{~mm}$ thickness), and also that mean if conventional resin denture base were $\leq 3 \mathrm{~mm}$ thick, it could be polymerized safely in microwave and this is in agreement with. ${ }^{(7,16,17)}$

The explanation for risk of porosities in thick (more than $3 \mathrm{~mm}$ thickness) specimens (when other causes are excluded) in spite of curing by microwave irradiation with lower wattage and long curing cycle (80 watts irradiation for 15 minutes per side, followed by 1.5 minutes at 500 watts) is that the exothermal heat did not dissipa- 
ted quickly to the surrounding investing material as in the thin section of specimen and the low wattage that was selected for curing did not able to spread the heat in gradual manner due to a lot of amount of monomer and polymer in the thick matter and thus the boiling point of the monomer which is $100.3^{\circ} \mathrm{C}$ was reached ${ }^{(18)}$, and as explained by Hasan ${ }^{(19)}$ thus evaporized monomer leave a porous acrylic resin, this is in agreement with other studies. ${ }^{(20,21)}$

Table (2): Student t-test analysis between porosity means of conventional and microwave heat cured acrylic resin specimens of $6 \mathrm{~mm}$ thickness.

\begin{tabular}{cccccc}
\hline Group & N & df & Mean+SD & t-value & $\boldsymbol{p}$-value \\
\hline C.h.a. 6mm & 10 & 1 & $0.931 \pm 0.716$ & -19.35 & $\mathrm{P}=0.0000^{*}$ \\
M.h.a. 6mm & 10 & 18 & $6.155 \pm 0.465$ & & \\
\hline
\end{tabular}

N: Number of samples; df: Degree of freedom; SD: Standard deviation; C.h.a: Conventional heat cured acrylic resin; M.h.a: Microwave heat cured acrylic resin.

*: Significant difference ( $\mathrm{P} \leq 0.05)$

Table (3): Student t-test analysis between porosity means of conventional and microwave heat cured acrylic resin specimens of $3 \mathrm{~mm}$ thickness.

\begin{tabular}{cccccc}
\hline Group & N & df & Mean \pm SD & t-value & $\boldsymbol{p}$-value \\
\hline C.h.a. 3mm & 10 & 1 & $0.873 \pm 0.40$ & -0.38 & $\mathrm{P}=0.71$ \\
M.h.a. 3mm & 10 & 18 & $0.968 \pm 0.673$ & & \\
\hline
\end{tabular}

N: Number of samples; df: Degree of freedom; SD: Standard deviation; C.h.a: Conventional heat cured acrylic resin; M.h.a: Microwave heat cured acrylic resin.

Table (4): Student $t-$ test analysis between porosity means of microwave heat cured acrylic resin specimens of different thickness.

\begin{tabular}{cccccc}
\hline Group & N & df & Mean+SD & t-value & p-value \\
\hline M.h.a. 3mm & 10 & 1 & $0.968 \pm 0.673$ & -20.06 & $0.0000^{*}$ \\
M.h.a. 6mm & 10 & 18 & $6.155 \pm 0.465$ & & \\
\hline
\end{tabular}

N: Number of samples; df: Degree of freedom; SD: Standard deviation; M.h.a: Microwave heat cured acrylic resin.

*: Significant difference $(\mathrm{P} \leq 0.05)$

Table (5): Student t-test analysis between porosity means of conventional heat cured acrylic resin specimens of different thickness.

\begin{tabular}{cccccc}
\hline Group & $\mathbf{N}$ & df & Mean + SD & t-value & $\boldsymbol{p}$-value \\
\hline C.h.a. $3 \mathbf{m m}$ & 10 & 1 & $0.873 \pm 0.40$ & -0.22 & $\mathrm{P}=0.83$ \\
C.h.a. 6mm & 10 & 18 & $0.931 \pm 0.716$ & & \\
\hline
\end{tabular}

$\mathrm{N}$ : Number of samples; df: Degree of freedom; SD: Standard deviation; C.h.a: Conventional heat cured acrylic resin. 
Student t-test analysis for the 4 groups showed significant difference of high percentage of porosity for the $6 \mathrm{~mm}$ thickness acrylic resin specimen which is nearly 7.6 times porous than $6 \mathrm{~mm}$ thickness of conventional heat cured acrylic resin, which is make decision that the conventional acrylic resin preferred to be used in microwave processing method for thin specimens sections only and not for thick sections as it is used in maxillofacial appliance as in (obturators) and this is in agreement with other studies ${ }^{(22,23,24)}$, who found that conventional resin specimens up to $(10 \mathrm{~mm})$ thickness polymerized in water bath were free of porous.

\section{CONCLUSIONS}

With in the limitations of this study, we conclude that conventional resin specimens polymerized in a water bath exhibited less percentage of pores, regardless of specimen thickness. The porosity percentage for Conventional resin specimens polymerized in microwave is indirectly proportional relation to the thickness of specimen, and this result is not true when Conventional resin specimens polymerized in water bath curing method (up to $6 \mathrm{~mm}$ thickness of specimen).

Conventional resin specimens polymerized in microwave exhibited significant porosity for $6 \mathrm{~mm}$ thickness specimens that is to say the microwave processing method used for specimens $(\leq 3 \mathrm{~mm})$ only when conventional acrylic resin were used.

\section{REFERENCES}

1. Craig RG. Restorative Dental Materials, $9^{\text {th }}$ ed. St. Louis. Mosby Co. 1993; Pp: 514-530.

2. Phillips RW. Phillips Science of Dental Materials, $7^{\text {th }}$ ed. New York. Saunders Co. 1993; p: 185.

3. Barbosa DB, Compagnoni MA, Leles CR. Changes in occlusal vertical dimention in microwave processing of complete dentures. Braz Dent J. 2002; 13(3): 197-200.

4. Nishii M. Studies on the curing of denture base resins with microwave irradiation: with particular reference to heat curing resins. J Osaka Dent Univ. 1968; 2: 23-40.

5. Ilbay SG, Guvener S, Alkumru HN. Pro- cessing dentures using a microwave technique. J Oral Rehabil. 1994; 21: 103109.

6. Bartoloni JA, Murchison DF, Wofford DT, Sarkar NK. Degree of conversion in denture base materials for varied polymerization techniques.J Oral Rehabil. 2000; 27: 488-493.

7. Compagnini MA, Barbosa DB, de Souza RF, Pero AC. The effect of polymerization cycles on porosity of microwaveprocessed denture base resin. $J$ Prosthet Dent. 2004; 91: 281-285.

8. Yannikakis S, Zissis A, Polyzois G, Andreopoulos A. Evaluation of porosity in microwave-processed acrylic resin using a Photographic method. J Prosthet Dent. 2002; 87: 613-619.

9. Al-Azzawi SI. Evaluation of some physical and mechanical properties of acrylic denture base materials cured by two diff-erent types of microwaves irradiation. MSc thesis., College of Dentistry. Univ-ersity of Baghdad. 1998.

10. Keller JC, Lautenschlager EP. Porosity reduction and its associated effect on the diametral tensile strength of activated acrylic resins. J Prosthet Dent. 1985; 53: 374-379.

11. Wolfaardt JF, Cleaton-Jones P, Fatti P. The occurrence of porosity in a heat cured poly(methyl methacrylate) denture base resin. J Prosthet Dent. 1986; 55: 393-400.

12. Vallittu PK, Ruyter IE, Buykuilmaz S. Effect of polymerization temperature and time on the residual monomer content of denture base polymers. Eur J Oral Sci. 1998; 106: 588-593.

13. De Oliveira VM, Leon BL, Del Bel Cury AA, Consani S. Influence of number and position of flasks in the monomer release, Knoop Hardness and porosity of a Microwave-cured acrylic resin. J Oral Rehabil. 2003; 30: 1104-08.

14. International organization for standardization, Specification 1567: denture base polymers. $2^{\text {nd }}$ ed. Geneva: ISO; 1998.

15. Bafile M, Graser GN, Myers ML, Li EK. Porosity in denture resin cured by microwave energy. J Prosthet Dent. 1991; 66: 269-274.

16. Al-Doori DII. Polymerisation of poly (methyl methacrylate) denture base materials by microwave energy. MSc thesis. 
College of Medicine, University of Wales. 2002.

17. Alkhatib MB, Goodacre CJ, Swartz ML, Munoz-Viveros CA, Andres CJ. Comparison of microwave-polymerized denture base resins. Int J Prosthodont. 1990; 3: 249-255.

18. Taylor PB. Acrylic resins: Their manipulation. J Am Dent Assoc. 1941; 28: 373-387.

19. Hasan RH. Denture Teeth Bond Strength to Heat Water Bath and Microwave Cured Acrylic Denture Base Materials: A Comparative Study. MSc. thesis. College of Dentistry. University of Mosul. 2002.

20. Reitz PV, Sanders JL, Levin B. The curing of denture acrylic resins by microw- ave energy. Physical properties. Quintessence Int. 1985; 8: 547-551.

21. Takahashi Y, Chai J, Takahashi T, Ha$\mathrm{bu} \mathrm{T}$. Bond strength of denture teeth to denture base resins. Int $J$ Prosthosdont. 2000; 13(1): 59-65.

22. Sanders JL, Levin B, Reitz PV. Porosity in denture acrylic resins cured by microwave energy. Quintessence Int. 1987; 18: 453-456.

23. Truong UT, Thomasz FGV. Comparison of denture acrylic resins cured by boiling water and microwave energy. Aust Dent J. 1988; 33: 201-204.

24. Gay WD, King GE, An evaluation of the cure of acrylic resin by three methods. $J$ Prosthet Dent. 1979; 42: 437-40. 